\title{
Seismic constraints on rock damaging in a failing mountain peak: the Hochvogel, Allgäu
}

\author{
Michael Dietze, GFZ German Research Centre for Geosciences, Section 4.6 Geomorphology, \\ Potsdam, Germany (mdietze@gfz-potsdam.de), \\ Michael Krautblatter, TU Munich, Department of Civil, Geo and Environmental Engineering, \\ Munich, Germany (m.krautblatter@tum.de), \\ Luc Illien, GFZ German Research Centre for Geosciences, Section 4.6 Geomorphology, \\ Potsdam, Germany (Iillien@gfz-potsdam.de), \\ Niels Hovius, GFZ German Research Centre for Geosciences, Section 4.6 Geomorphology, \\ Potsdam, Germany (hovius@gfz-potsdam.de)
}

\begin{abstract}
Large rock slope failures play a pivotal role in long-term landscape evolution and are a major concern in land use planning and hazard aspects. While the failure phase and the time immediately prior to failure are increasingly well studied, the nature of the preparation phase remains enigmatic. This knowledge gap is due, to a large degree, to difficulties associated with instrumenting high mountain terrain and the local nature of classic monitoring methods, which does not allow integral observation of large rock volumes. Here, we analyse data from a small network of up to seven seismic sensors installed during July-October 2018 (with 43 days of data loss) at the summit of the Hochvogel, a $2592 \mathrm{~m}$ high Alpine peak. We develop proxy time series indicative of cyclic and progressive changes of the summit. Fundamental frequency analysis, horizontal-to-vertical spectral ratio data and end-member modelling analysis reveal diurnal cycles of increasing and decreasing coupling stiffness of a 126,000 m 3 large, instable rock volume, due to thermal forcing. Relative seismic wave velocity changes also indicate diurnal accumulation and release of stress within the rock mass. At longer time scales, there is a systematic superimposed pattern of stress increases over multiple days and episodic stress release within a few days, expressed in an increased emission of short seismic pulses indicative of rock cracking. We interpret our data to reflect an early stage of stick slip motion of a large rock mass, providing new information on the development of large-scale slope instabilities towards catastrophic failure.
\end{abstract}

This paper is the first version of a peer reviewed preprint uploaded to EarthArXiv, and submitted to "Earth Surface Processes and Landforms".

Potsdam, 04 June 2020 


\title{
Seismic constraints on rock damaging in a failing mountain peak: the Hochvogel, Allgäu
}

\author{
M. Dietze ${ }^{1}$, M. Krautblatter ${ }^{2}$, L. Illien ${ }^{1}$, N. Hovius ${ }^{1,3}$ \\ ${ }^{1}$ GFZ German Research Centre for Geosciences, Section 4.6 Geomorphology, Potsdam, Germany \\ ${ }^{2} \mathrm{TU}$ Munich, Chair of Monitoring, Analysis and Early Warning of Landslides, Department of Civil, Geo \\ and Environmental Engineering, Munich Germany \\ ${ }^{3}$ Institute of Geosciences, University of Potsdam, Germany
}

\section{Key Points:}

- Continuous and discrete failure preparation signals of a large-scale slope instability are seismically recorded

- Reversible and irreversible mechanisms at the diurnal, multi-day and seasonal scale are quantified

- We infer an early stage of stick slip motion and thermally forced diurnal stress release and rock mass stiffness changes 


\section{Abstract}

Large rock slope failures play a pivotal role in long-term landscape evolution and are a major concern in land use planning and hazard aspects. While the failure phase and the time immediately prior to failure are increasingly well studied, the nature of the preparation phase remains enigmatic. This knowledge gap is due, to a large degree, to difficulties associated with instrumenting high mountain terrain and the local nature of classic monitoring methods, which does not allow integral observation of large rock volumes. Here, we analyse data from a small network of up to seven seismic sensors installed during July-October 2018 (with 43 days of data loss) at the summit of the Hochvogel, a $2592 \mathrm{~m}$ high Alpine peak. We develop proxy time series indicative of cyclic and progressive changes of the summit. Fundamental frequency analysis, horizontal-to-vertical spectral ratio data and end-member modelling analysis reveal diurnal cycles of increasing and decreasing coupling stiffness of a $126,000 \mathrm{~m}^{3}$ large, instable rock volume, due to thermal forcing. Relative seismic wave velocity changes also indicate diurnal accumulation and release of stress within the rock mass. At longer time scales, there is a systematic superimposed pattern of stress increases over multiple days and episodic stress release within a few days, expressed in an increased emission of short seismic pulses indicative of rock cracking. We interpret our data to reflect an early stage of stick slip motion of a large rock mass, providing new information on the development of large-scale slope instabilities towards catastrophic failure.

\section{Introduction}

Gravitational mass wasting is the dominant geomorphic process shaping mountain peaks. The release of large rock volumes on steep slopes marks the start of a sediment cascade that evolves to the terrestrial sediment flux into the oceans. Its suddenness, velocity and limited predictability renders gravitational mass wasting hazardous yet hard to constrain in terms of drivers and triggers, and mechanisms and their temporal evolution. Classic approaches to studying mass wasting processes are either ex post investigations of the failure mechanism (Frayssines \& Hantz, 2006), volume and environmental conditions before and during the event (D'Amato et al., 2016), long-term monitoring, often with remotely sensed imagery, or, increasingly, point measurements from dedicated sensors at sites with known or expected activity (Di Maio et al., 2010; Lévy et al., 2010; Dixon et al., 2018; Collins et al., 2018; Walter et al., 2020). None of these approaches can provide detailed continuous insight into the activity with high temporal resolution, beyond the "point dimension" and throughout the wider process domain, including the downslope pathway of a failing rock mass.

A mass wasting event is preceded by a phase of preparation, during which a set of intrinsic and extrinsic processes drive a rock mass to a state of instability, making it susceptible to trigger mechanisms such as loading with precipitation, seismic ground shaking, wind force fluctuation, and freeze-thaw transitions (see for example Stock et al. (2013) for a summary of trigger mechanisms). While the preparation phase is crucial for hazard anticipation, its mechanisms are little known. It is clear, however, that rock slope failures predominantly develop in the steepest rock flanks of mountains under high topographic stresses (Leith et al., 2014). There, differential stress conditions can be above the micro crack initiation threshold and favour crack coalescence along the weakest trajectories in the rock mass, i.e. the critical path (Einstein et al., 1983). Once a rock mass starts to move, deformation accumulates along that critical path, and shear stress concentrates on a decreasing number of remaining rock bridges, initiating subcritical and critical fracture propagation in these preferential damage zones (Kemeny, 2003). In the final phase of rock slope failure, when most rock bridges have been destroyed, the rock mass often exhibits cyclic accelerations and decelerations referred to as "stick-slip failure" (e.g., Yamada et al., 2016; Schöpa et al., 2018). This behaviour is thought to be 
controlled by macro-roughness along the sliding plane that inhibits sliding and promotes stress concentration along the affected obstacles in the sliding plane and release in episodic deformation (Borri-Brunetto et al., 2003; Saettele et al., 2015). In this phase, changes in hydrostatic pressure and seismic excitation can initiate significant acceleration of a sliding rock mass by enhancing shear stress on remaining obstacles. This is due to transiently enhanced overall shear stress, reduced total friction of the surrounding sliding plane, and the effect of water on rock fracture mechanical strength (Voigtländer et al., 2018). As shear planes are mostly inaccessible, insight into spatial and temporal patterns of stress concentration and fracture propagation is difficult to achieve with classic approaches, especially under natural conditions.

In the last decade, networks of seismic sensors have been established as a complimentary tool to overcome some of the limitations of other measurement and monitoring approaches. Seismic sensors can record ground motion caused by processes acting at or close to the Earths surface. In general, seismic networks can i) detect mass wasting activity, ii) locate and track the process in space, and iii) infer kinetic and anatomic details of a process event. The application fields of environmental seismology (Burtin et al., 2014; Larose et al., 2015) comprise, for example, time-resolved investigation of the evolution of slope instabilities (Mainsant et al., 2012; Schöpa et al., 2018), detection and quantification of event activity from the catchment to the global scale (Lacroix \& Helmstetter, 2011; Dammeier et al., 2011; Ekström \& Stark, 2013; Fuchs et al., 2018), tracking of mass movements in space (Burtin et al., 2016; Cook et al., 2018; Pérez-Guillén et al., 2019; Walter et al., 2020), inversion of seismic signals for event kinetics (Allstadt, 2013; Ekström \& Stark, 2013), and attribution of events to drivers and triggers (Helmstetter \& Garambois, 2010; Burtin et al., 2013; M. Dietze, Turowski, et al., 2017).

In addition to investigating the seismic signals emitted by mass wasting processes, it is possible to use random background signals (ambient noise) to survey the material properties of landforms (I. Welch \& McLamore, 1973). There are several techniques that are sensitive to state changes of the near-surface materials in eroding landscapes. A classic technique is the horizontal to vertical spectral ratio (HVSR) analysis (Nogoshi \& Igarashi, 1971; Nakamura, 1989). It has been widely used to estimate the near-surface structure of sites (for a review see Del Gaudio et al., 2014), though there is controversy about the confidence and robustness of quantitative inversions for material properties (see for example discussion in Overduin et al., 2015). Bottelin et al. (2013) used seismic sensors to monitor changes in the fundamental frequencies of an unstable rock column in the French Alps as a function of temperature and precipitation. Weber, Fäh, et al. (2018) applied the same technique to the Matterhorn, identifying cyclic as well as cumulative damage evolution. Seismic noise cross correlation (Snieder, 2004; Sens-Schönfelder \& Wegler, 2006) has the potential to detect subtle, relative changes in the seismic wave velocity, termed $d v / v$ throughout this text. The technique can be applied using the individual components of a single seismic station or records from seismic station pairs, given that both stations are within the coherence range of the ambient wave field. The seismic wave velocity is affected by a series of factors, such as rock temperature, ground moisture, accumulated rock damage and mechanical stress (Snieder, 2004; Larose et al., 2015; Clements \& Denolle, 2018; M. Dietze et al., submitted). HVSR, fundamental frequency and $d v / v$ are valuable proxies of material state, because they provide information on the average state of the medium within the seismic network aperture, not just at a point. Moreover, these proxies can be recorded continuously, at arbitrary high resolution and with little infrastructural effort, so that the evolution of the material state can be tracked over time and changing boundary conditions.

Here we study the summit of the Hochvogel, a $2592 \mathrm{~m}$ high solitary peak in the South German Alps. We exploit the utility of a small, telemetered seismic network on the summit, which was operational during a period in which a large rock volume near the summit was undergoing failure preparation. We investigate seismically evident patterns of 

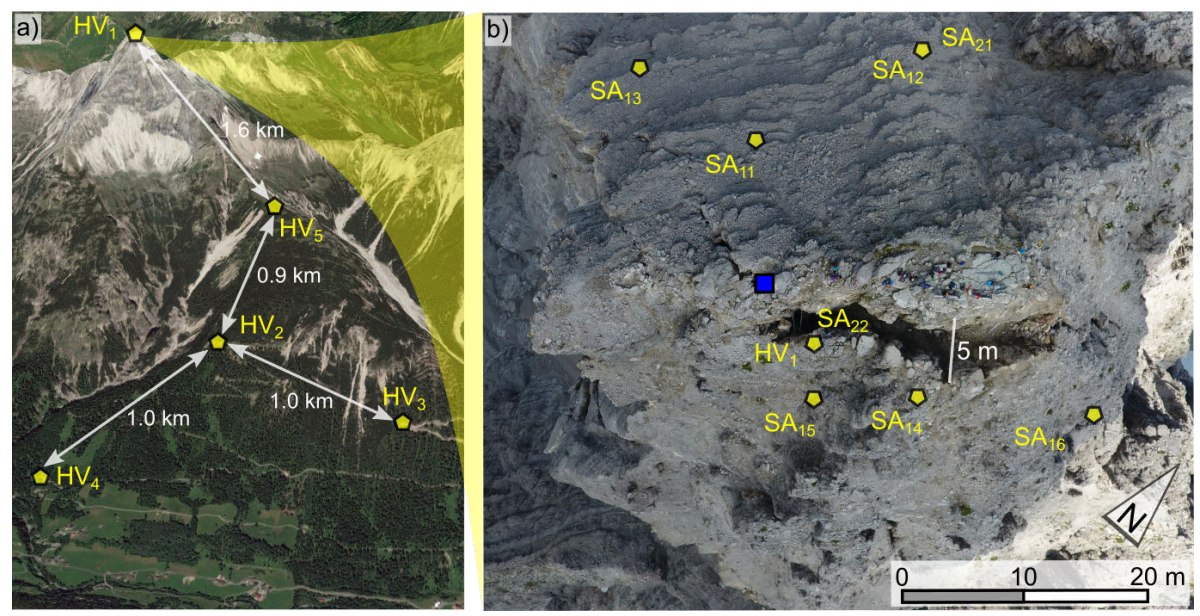

Figure 1. Study area and instrumentation. a) Oblique view from the Austrian side towards the north. The $2592 \mathrm{~m}$ high Hochvogel with station $\mathrm{HV}_{1}$ on the summit is in the background, the town of Hinterhornbach in the foreground. $\mathrm{HV}_{1}$ to $\mathrm{HV}_{5}$ are the seismic stations forming the hillslope network to monitor mass wasting activity. b) Close-up top view of the Hochvogel summit with a $>25 \mathrm{~m}$ long and 2-4 m wide main fracture in the centre. Yellow polygons depict six seismic sensors of the small aperture summit network, station $\mathrm{HV}_{1}$ is the same as in a). Blue square depicts data logger and GSM antenna. Figures S1 1-3 provide further details of the summit and the instrumentation.

summit deformation, how these are controlled by environmental conditions, and how they translate into mechanistic activity.

\section{Study site and instrumentation}

The Hochvogel is a solitary, $2592 \mathrm{~m}$ high peak in the Eastern Allgäu Alps, on the border between Germany and Austria. It is formed of folded and thrusted upper Triassic dolomite (Hauptdolomit), which forms competent decimetre to metre thick beds, $20^{\circ}$ dipping to the NNW in the summit area. Extensive vertical fracture sets run perpendicular to the general dip, giving rise to an intensely fractured fabric. Formation of large fractures in the summit area was first recorded in the late nineteenth century, and a progressively accelerating rock slide has developed since the 1950s. Catastrophic failure could mobilise up to $260,000 \mathrm{~m}^{3}$ of rock in several subunits (Krautblatter et al., 2019) along a failure plane located on two large, NE-SW trending fracture systems. In 2018, the southeastern, main fracture had already opened by $2-4 \mathrm{~m}$, and it continues opening at a rate of a few mm per month (Krautblatter et al., 2019). The unstable rock mass has moved downslope by several metres and developed a severe state of fracturing (Fig. SI 1-3).

To monitor activity at the Hochvogel summit as well as any mass wasting processes in the southeastern mountain slope, we installed a nested network of seismic stations (Fig. 1). At the summit we installed a small aperture network (33 $\mathrm{m}$ average, $73 \mathrm{~m}$ maximum spacing) consisting of six PE6B one-component $4.5 \mathrm{~Hz}$ geophones, three on the less fractured, relatively stable German side $\left(\mathrm{SA}_{11}-\mathrm{SA}_{13}\right)$ and three on the failing Austrian side $\left(\mathrm{SA}_{14}-\right.$ $\mathrm{SA}_{16}$ ). The sensors were connected by $100 \mathrm{~m}$ long cables to a Nanometrics Centaur data logger that recorded the ground velocity values at $200 \mathrm{~Hz}$ with a gain of 40 . These seismic data were transmitted to the GFZ data server every five minutes. The network was operational from 10 July 2018. However, after a lightning strike of the station on $1 \mathrm{Au}-$ 
gust 2018 no data were recorded for 43 days until 12 September 2018. From this date we operated a set of two PE6B $4.5 \mathrm{~Hz}$ geophones $\left(\mathrm{SA}_{21}\right.$ a 1 -component and $\mathrm{SA}_{22}$ a 3 component sensor) and Digos DataCube ${ }^{3}$ ext loggers, installed in an aluminium case with a $2 \mathrm{~cm}$ thick concrete bed. To record slope activity below the summit, we installed five seismic stations with spacings between 0.9 and $1.6 \mathrm{~km}$. Station $\mathrm{HV}_{1}$ contains the same setup as $\mathrm{SA}_{22}$ and was used in this study as additional summit station. Here we only consider data from the small aperture array at the summit, for the periods $10 \mathrm{July}-1 \mathrm{Au}-$ gust and 12 September-12 October.

\section{Data processing}

All seismic data were processed with the software $\mathrm{R}$ v. 3.6.3 (R Development Core Team, 2020), using the package eseis v. 0.5.0 (M. Dietze, 2018a, 2018b). The Supporting Information (SI) contains dedicated $\mathrm{R}$ scripts of all major processing and analysis steps. The underlying data is available via GFZ Data Services (M. Dietze \& Krautblatter, 2020). For fundamental frequency analysis we calculated averaged (P. Welch, 1967) spectra for non-event periods (Bottelin et al., 2013) of the summit network sensors. For this we calculated an STA-LTA ratio (Allen, 1982) and flagged periods with a ratio $>$ 1.5 as event-contaminated. These periods were excluded from the subsequent step of spectra calculation. The spectra were calculated for $5 \mathrm{~s}$ windows without overlap, which were then stacked to non-overlapping hourly spectra. Each of these spectra was subsequently normalised. Finally, we executed a 5 sample running average filter in frequency and time. Since the PE6B geophone sensors have a natural frequency of $4.5 \mathrm{~Hz}$, we focus our analysis on frequencies above this limit, knowing that we most likely miss the lowest fundamental frequency band of the rock mass under investigation (e.g. Lévy et al., 2010; Bottelin et al., 2013).

For the HVSR analysis we calculated spectra of station $\mathrm{HV}_{1}$ and $\mathrm{SA}_{22}$ for the vertical and horizontal components within $5 \mathrm{~s}$ windows with $50 \%$ overlap. We then calculated the ratio of the corresponding horizontal and vertical spectra and stacked these to hourly results. To quantify the spectral modes inherent to the HVSR data, we applied end-member modelling analysis (EMMA) to the data set. EMMA (E. Dietze \& Dietze, 2019) is a statistical technique, which allows unmixing multimodal data, and describing it as a linear combination of loadings (the fundamental underlying spectra distributions) and scores (the relative contribution of each loading to each sample). EMMA was originally developed for decomposition of high resolution grain-size spectra, but it can be extended to other kinds of compositional data (i.e., data that is non-negative and where each sample is described by a constant sum). To be able to apply EMMA, we truncated the HVSR data set to the most variable frequency range and normalised the spectral ratios of each hourly time slice between 0 and 1 . Since we were interested in identifying the position and shape of the spectral modes as well as their relative contributions to a temporal sample, but not in the absolute intensity of the HVSR amplitudes, this normalisation step is valid. We followed the generic deterministic EMMA protocol (using the EMMAgeo package v. 0.9.8, E. Dietze \& Dietze, 2019) and tested between two and six end-members for plausibility of the results. These plausibility checks were based on model quality (i.e. time-resolved and frequency-resolved variance explained by the model), the degree of unmixing of the frequency distributions and the interpretative meaningfulness of the unmixed frequency distributions and their evolution with time.

We estimated relative velocity changes from ambient noise cross correlation. First, the seismic traces were pre-processed to reduce the impact of erratic, high amplitude signals. We trimmed the seismic records to $10 \mathrm{~min}$ long segments, downsampled to $50 \mathrm{~Hz}$, detrended and filtered in the $4-16 \mathrm{~Hz}$ frequency range. We normalised amplitudes by spectral whitening, setting all the amplitudes in the Fourier spectrum to 1 and performed 1-bit normalisation. In the first time period, we performed cross correlations between all vertical component sensor pairs. In the second period, since only two stations were 
operating, located on different sides of the main fracture, we performed single station cross correlation (Hobiger et al., 2014) on station $\mathrm{SA}_{22}$ using the three combinations NorthVertical, East-Vertical, and East-North. We stacked the obtained correlation functions to 30 min non-overlapping averages and stored them in a correlation matrix $C\left(t_{i}, \tau\right)$ where $t_{i}$ and $\tau$ is the lapse time in the correlation process. To infer relative velocity changes $\mathrm{dv} / \mathrm{d}$, we used the stretching technique (Sens-Schönfelder \& Wegler, 2006): Each of the 30 min correlation functions were be stretched or compressed depending on their relative velocity change compared to a reference $(\tau)$. For the two time periods, we computed the average correlation function $(\tau)$ and used it as a reference. We calculated the correlation coefficient $R\left(t_{i}, \varepsilon_{j}\right)$ between stretched versions of this reference with each correlation functions stored in $C\left(t_{i}, \tau\right)$ such as

$$
R\left(t_{i}, \varepsilon_{j}\right)=\int_{\tau_{1}}^{\tau_{2}} C\left(t_{i}, \tau\right) \xi\left(\tau *\left(1+\varepsilon_{j}\right)\right) \mathrm{d} \tau
$$

where $\varepsilon_{j}$ indicates stretch-values tested in the time window $\left[\tau_{1} \tau_{2}\right]$. We used $\tau_{1}=0.5 \mathrm{~s}$ to avoid unwanted source effects and used a window duration of $3 \mathrm{~s}$. For the second time period, we averaged the measurements between the three combinations by stacking their three corresponding matrices $R\left(t_{i}, \varepsilon_{j}\right)$. Finally, we extract those $d v\left(t_{i}\right) / v$ values for which $\varepsilon_{j}$ yielded the maximum correlation coefficient $R\left(t_{i}, \varepsilon_{j}\right)$, and only kept values where the correlation coefficient was at least 0.5 .

In addition to the continuous analysis we isolated discrete seismic events in the data of the summit network. We picked events using a classic STA-LTA ratio routine (Allen, 1982), applied to the $10-40 \mathrm{~Hz}$ filtered signal envelopes. The routine was applied with a low detection threshold (on-ratio $=3$, off-ratio $=1$, STA-window $=0.5 \mathrm{~s}$, LTA-window $=120 \mathrm{~s}$ ). This yielded many false positives but also guaranteed detection of small events. All potential events were tested against automatic rejection criteria. We required an event to have a minimum duration of $0.2 \mathrm{~s}$ as well as a maximum duration of $10 \mathrm{~s}$. We assumed that events shorter than $0.2 \mathrm{~s}$ are associated with random sources such as rain drop impacts (M. Dietze, Mohadjer, et al., 2017), and events longer than 10 s are unlikely to be linked to discrete geomorphic activity at the summit. A further rejection criterion imposed that an event had to be detected by at least two stations with a time difference of not more than $0.1 \mathrm{~s}$. This rule enforces that signals must travel across the entire network in a time that corresponds to an apparent seismic wave velocity of at least $730 \mathrm{~m} / \mathrm{s}$, a threshold well below typical values for limestone of different origin and degree of fracturing (Assefa et al., 2003; Helmstetter \& Garambois, 2010; M. Dietze, Mohadjer, et al., 2017). Signals with longer detection time differences are usually a result of the coincidence of unrelated signals or waves travelling through air (about $330 \mathrm{~m} / \mathrm{s}$ velocity) before coupling to the ground. All remaining events were then checked manually for plausibility: telltales of genuine geomorphic signals include spindle shaped seismograms, and consistent amplitude and frequency decrease as well as onset shifts with distance between source and sensor (for details see Hibert et al., 2011; Hammer et al., 2015; M. Dietze, Mohadjer, et al., 2017; Vouillamoz et al., 2018).

Meteorological data for the summit were approximated by scaling hourly values of a station near Oberstdorf, $12 \mathrm{~km}$ to the west (DWD, 2019). Temperature scaling by $0.6{ }^{\circ} \mathrm{C}$ per $100 \mathrm{~m}$ altitude increase results in a downward shift of $12{ }^{\circ} \mathrm{C}$ of summit temperatures. For precipitation the German Weather Bureau offers hourly gridded data (DWD, 2019). However, for the time of interest there are data gaps. Therefore, we calculated a transfer function between gridded values at the peak and the Oberstdorf data for adjacent periods with data and use this relationship to infer precipitation data also for the peak during relevant data gaps. 


\section{Results}

\subsection{Meteorological conditions}

Meteorological dynamics define an important set of boundary conditions for the activity of the summit. The scaled air temperature records (Fig. 2) are dominated by the diurnal cycle, with amplitudes of about $18^{\circ} \mathrm{C}$ in the first instrumentation period (10 July-01 August) and about $22^{\circ} \mathrm{C}$ in the second period (10 September-12 October). Superimposed on these fluctuations was a rising trend from 10 to $23^{\circ} \mathrm{C}$ (interrupted by stable temperatures between 16-24 July) in the first period and a somewhat decreasing trend from $14-10^{\circ} \mathrm{C}$ during the second period. Precipitation events occurred throughout the record time (Fig. 2 e), but lasted only a few hours to a day, with usually less than $6 \mathrm{~mm} / \mathrm{h}$ peak intensities. Precipitation events did not coincide with changes in any of the seismic data sets.

\subsection{Continuous seismic observations at the summit}

Continuous seismic observations include the results of the fundamental frequency, HVSR and $d v / v$ analyses, which will be used to infer material property changes of the rock mass. Here, we offer a condensed, synoptic report of the multitude of observed metrics. The SI contain results from all sensors. In general, sensors from the instable mass on the southeast side of the Hochvogel summit $\left(\mathrm{SA}_{14}, \mathrm{SA}_{15}, \mathrm{SA}_{16}, \mathrm{SA}_{22}\right)$ did not record a systematic pattern of fundamental frequency evolution on the vertical component. In contrast, stations on the stable mass, opposite $\left(\mathrm{SA}_{11}, \mathrm{SA}_{12}\right)$, did reveal consistent vertical component fundamental frequency bands. These were best expressed at station $\mathrm{SA}_{11}$, located closest to the summit and the main fracture (see Fig. SI 5 and $2 \mathrm{a}$ ). We used the three component stations $\mathrm{HV}_{1}$ (first period) and $\mathrm{SA}_{22}$ (second period) for HVSR analysis. Both stations were located on the instable mass adjacent to the main crack. The $d v / v$ analysis yielded between-station correlation coefficients $>0.5$ for the station pair $\mathrm{SA}_{12}$ and $\mathrm{SA}_{13}$ while all other pairs did not show meaningful signal coherence. Likewise, the between-components analysis for $\mathrm{SA}_{22}$ during the second period did not yield correlation coefficients above 0.5 and results were thus discarded.

The two monitoring periods (10 July to 01 August and 12 September to 12 October, separated by 43 days without data) showed contrasting results of the analysed monitoring metrics. The fundamental frequency of the vertical component of stations installed near the top of the stable northern rock mass $\left(\mathrm{SA}_{21}\right.$ and $\mathrm{SA}_{22}$, Fig. 2 a) ranged between 24 and $28 \mathrm{~Hz}$. There were also higher frequencies present in the data set (see Fig. SI 5) but they are either multiples of the lower frequency band from Fig. 2 a or frequencies corresponding to higher order bending modes (Bottelin et al., 2013). In the first period, the $24-28 \mathrm{~Hz}$ band exhibited prominent multi-day cycles, consisting of four to seven days of continuous rise of the fundamental frequency by two to three $\mathrm{Hz}$ followed by a sudden drop, almost back to the initial values. Four such cycles are visible in Fig. 2 a, with drops around 10, 15, 21, 29 July. In the second period, the fundamental frequency was dominated by diurnal cycles without clear multi-day effects. On the instable southern rock mass, no fundamental frequency pattern was found in the vertical component (see Fig. SI 5).

The horizontal seismic sensor component (Fig. 2 b) exhibited a fundamental frequency band between 7 and $10 \mathrm{~Hz}$, though weakly expressed, with diurnal cycles throughout both periods. Multi-day patterns were suppressed (first period) or absent (second period). A data gap during the second period was due to event contaminated time slices, which were removed, thus affecting the moving window temporal averaging process.

Diurnal cycles were also visible in the HVSR results (Fig. 2 c), most clearly during the first survey period (10 July to 01 August). The higher resolution of this record in the time dimension allowed a more detailed analysis of the data. This revealed that 

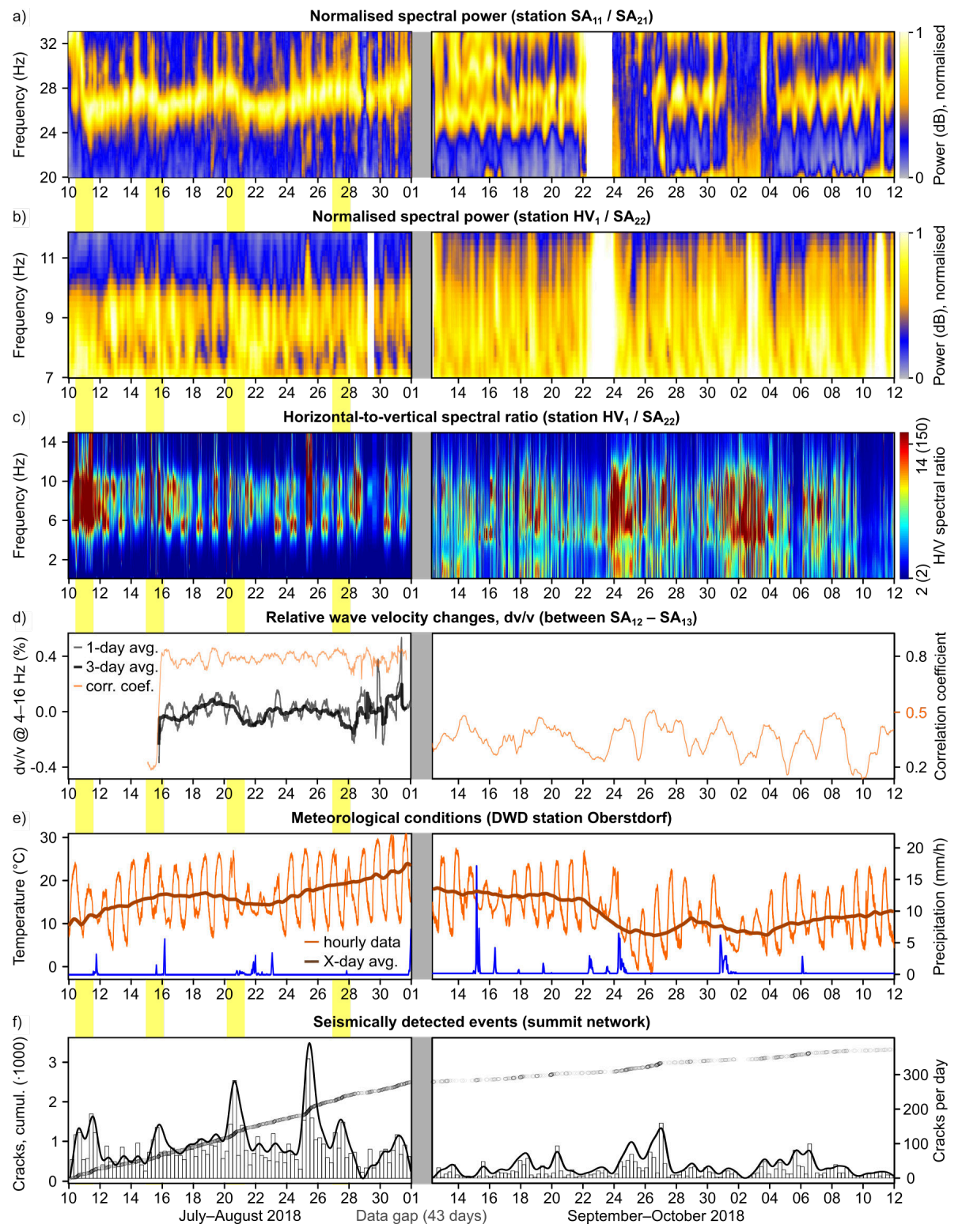

Figure 2. Seismic properties of the Hochvogel summit network in the summer (left panels) and autumn (right panels) survey period. a) Evolution of the fundamental frequency of vertical component station $\mathrm{SA}_{11}$ ( $\mathrm{SA}_{21}$ after reinstallation on 12 September 2018). b) Evolution of the fundamental frequency of the horizontal components of station $\mathrm{HV}_{1}\left(\mathrm{SA}_{22}\right.$ after reinstallation on 12 September 2018). c) HVSR evolution for the same stations as in b). Values in the second period are given in parentheses of the legend labels. d) Relative wave velocity change $(d v / v)$ between the stations $\mathrm{SA}_{12}$ and $\mathrm{SA}_{13}$ (left panel). Thin grey line depicts 1-day running average smoothened data, Thick black line shows 3-day running average results. Orange line depicts correlation coefficient of the signal pairs. Only $d v / v$ data above $r=0.5$ is shown. e) Meteorological conditions at a station $12 \mathrm{~km}$ west of the summit. f) Seismically detected events, shown as cumulative event plot (open circles) and 6-hour histograms of daily crack rates. Kernel density estimate (solid bold line, 6 hour kernel bandwidth) is plotted on top of histogram for better visual interpretation of crack rate evolution. 
the HVSR was around 5-7 Hz during night time and around 9-10 $\mathrm{Hz}$ during daytime. This diurnal pattern was distorted during episodes when the vertical fundamental frequency drops occurred (Fig. 2 a).

\subsection{End-member modelling}

To better characterise and quantify the underlying frequency patterns and their contribution to the data through time, we performed end-member modelling analysis on the $2-15 \mathrm{~Hz}$ band of the normalised HVSR data (Fig. 3 a). Models with two $(62.2 \%$ of total variance explained for first period, $55.9 \%$ for second period), three $(75.6 \%, 70.0$ $\%)$, five $(77.9 \%, 70.8 \%)$ and six $(80.0 \%, 75.3 \%)$ end-members showed mostly lower performance than the model with four end-members $(80.6 \%, 71.9 \%)$. More importantly, models with other than four end-members did not yield meaningful unmixing results, usually exhibiting multimodal or broad frequency distributions or largely overlapping end-members (see SI for all tested models). The two four-end-member models for the survey periods 10 July-01 August and 12 September-12 October allowed describing the data set in the time domain (i.e., the hourly time windows of HVSR data) with $R^{2}=$ 0.89 (first period) and $R^{2}=0.79$ (second period). The frequency domain (i.e., the model representation of individual HVSR distributions, cf. Fig. 3 c) is described with $R^{2}=$ 0.73 (first period) and $R^{2}=0.65$ (second period, mostly because frequencies above 10 $\mathrm{Hz}$ did not contribute much to the data set overall). The shapes of the end-member loadings (Fig. 3 d) agree with the visual inspection of the raw HVSR data (Fig. 2 c). During the first survey period, two recurring frequency modes at 5.4 and $9.0 \mathrm{~Hz}$ are represented by $\mathrm{EM}_{1}$ and $\mathrm{EM}_{3}$, while the transitional stages between these two are formed by $\mathrm{EM}_{2}$ (modal frequency at $7.0 \mathrm{~Hz}$ ). $\mathrm{EM}_{4}$ covers a broader frequency band, ranging from 10-15 Hz. During the second survey period, $\mathrm{EM}_{1}$ to $\mathrm{EM}_{3}$ had consistently shifted their modal frequencies, to $6.4 \mathrm{~Hz}, 7.4 \mathrm{~Hz}$ and $9.8 \mathrm{~Hz}$, respectively. The $\mathrm{EM}_{4}$ from the first period was no longer visible, but $\mathrm{EM}_{3}$ showed a broad shoulder towards higher frequencies. During this second period, $\mathrm{EM}_{4}$ was in the frequency range $2-5 \mathrm{~Hz}$ with a modal frequency of $3.2 \mathrm{~Hz}$. This new low frequency variability in the data is also visible in the normalised (Fig. 3 a) as well as the raw (Fig. 2 c) HVSR data set. In terms of end-member scores (Fig. 3 b), $\mathrm{EM}_{1}$ provided high contributions to the HVSR data mostly during the early hours of the day, and $\mathrm{EM}_{3}$ during the late hours. $\mathrm{EM}_{2}$ takes an intermediate role, between $\mathrm{EM}_{1}$ and $\mathrm{EM}_{3}$. In the first survey period, $\mathrm{EM}_{4}$ mainly contributed to HVSR data during episodes of enhanced seismic event rates (see below).

Noise cross correlation analysis yielded meaningful results only for the station pair $\mathrm{SA}_{12}-\mathrm{SA}_{13}$ (Fig. $2 \mathrm{~d}$ ). Even there, the correlation among the stations did not reach $>$ 0.8 before 16 July. From that date on, the 1-day running averaged $d v / v$ data shows a diurnal pattern superimposed on a longer-term trend. That longer term trend is better visible in the 3-day running average curve: Coincident with the periods of vertical fundamental frequency (Fig. 2 a) and distortions of the bimodal HVSR pattern (Fig. 2 c), the $d v / v$ trend showed abrupt decreases by about $0.3 \%$ around 15, 21 and 28 July 2018.

\subsection{Discrete seismic events}

The summit network recorded a series of discrete signals of diverse properties with respect to duration, evolution and spectral content. The STA/LTA event detection algorithm and application of the subsequent rejection criteria yielded a total of 2490 and 845 potential near-surface events for the first and second survey period, respectively. One class of detected events had the hallmarks of rock cracking (e.g., Senfaute et al., 2009): one to two seconds long, erratic, single pulses suddenly emerging from an otherwise silent record, with frequencies predominantly between 30 and $80 \mathrm{~Hz}$. These events showed a distinct evolution during the two survey periods. Between 10 July and 01 August, the average event rate was 100 cracks per day, with episodes of enhanced activity on 10-12, 15-16, 21-22, 24-26 and 27-28 July (Fig. 2 f). In the second period, 12 September to 


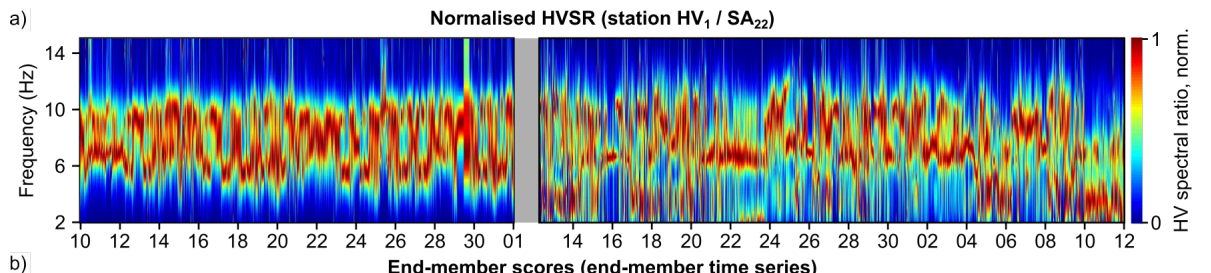

b) End-member scores (end-member time series)
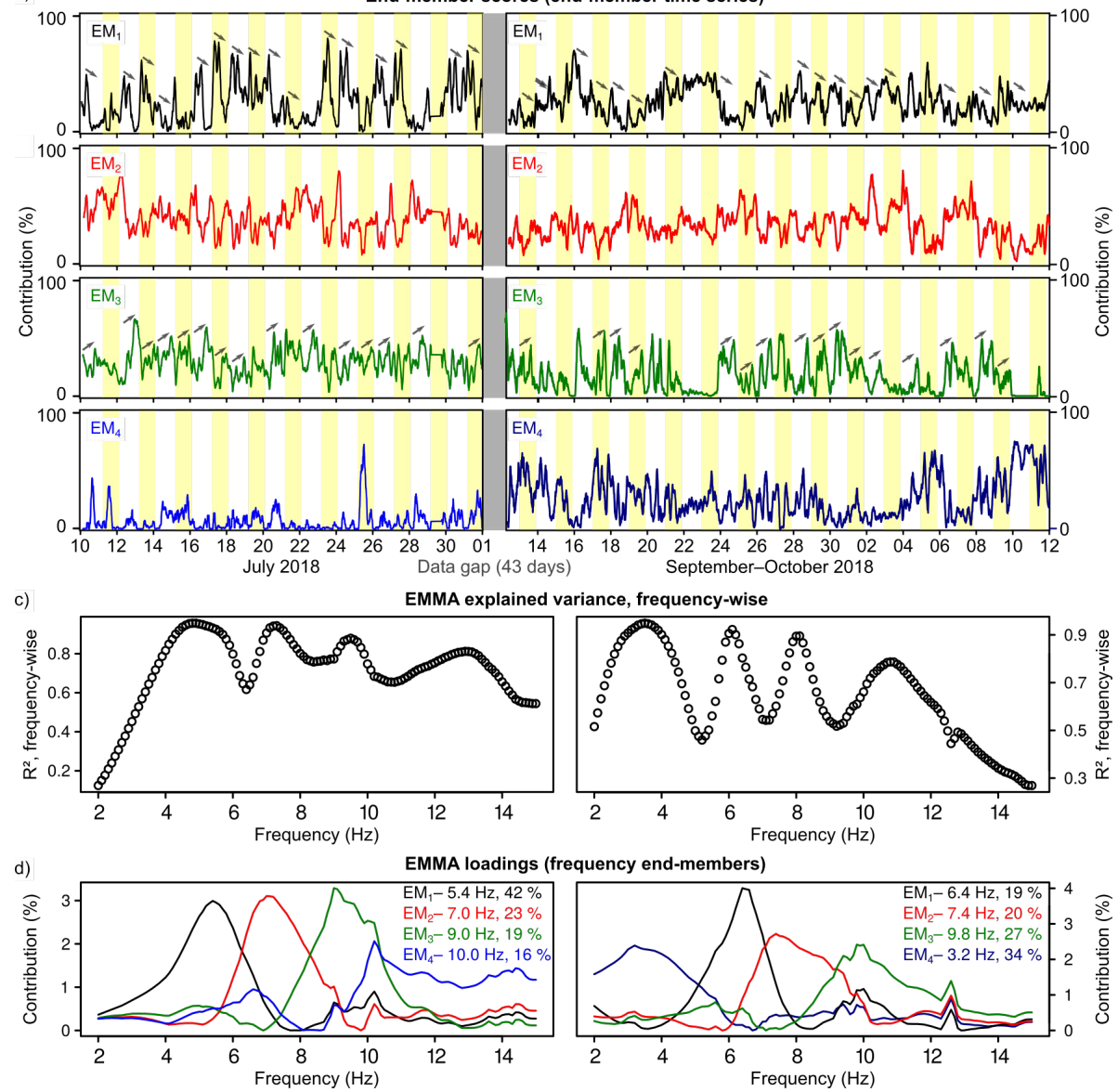

Figure 3. End-member modelling analysis results. a) Normalised HVSR data for both monitoring periods. b) End-member scores (contribution of each end-member to a time slice of a) of all four end-members. Alternating yellow and white bars depict single days. Semi transparent small arrows illustrate days of typical decrease and increase of end-member contribution to the signals with the course of the day. c) Model $\mathrm{R}^{2}$ in the frequency space. d) End-member loadings (frequency shapes of the four end-members). Legend denotes modal frequency and in parentheses the explained variance of each end-member. 
a)

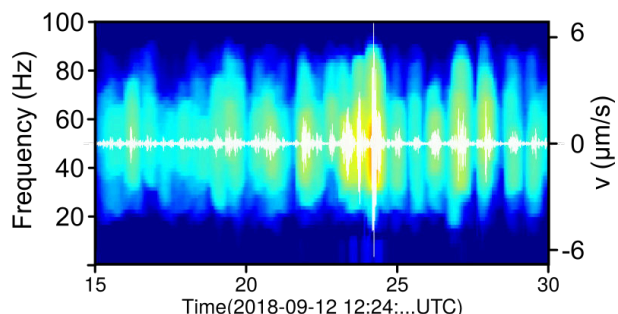

b)

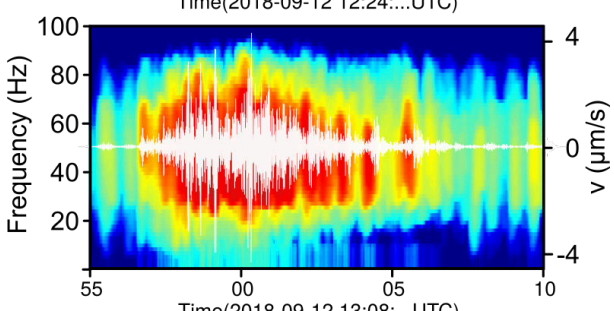

c)

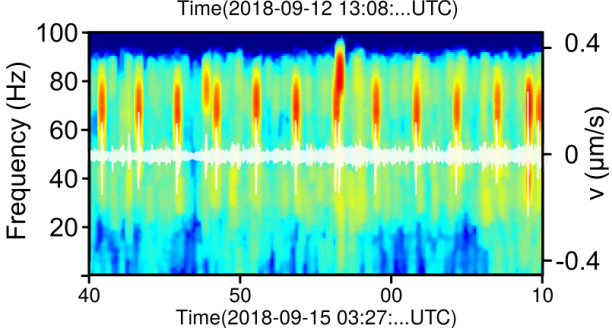

d)

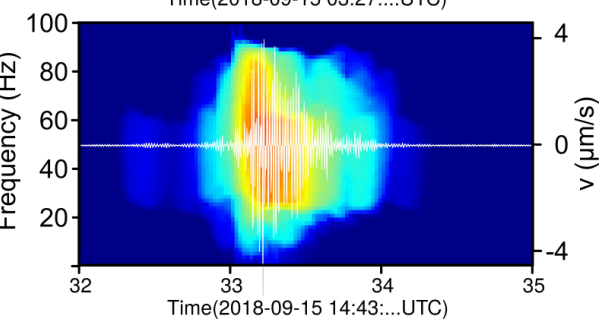

Figure 4. Seismic signals due to different sources, as recorded by the Hochvogel summit network (station $\mathrm{SA}_{22}$ ). The plots show spectrograms (scaled between -160 and -100 $10 \log _{10}\left(\mathrm{~m}^{2} / \mathrm{s}^{2}\right) / \mathrm{Hz}$, except for $\mathrm{c}$ ), which is scaled in the range -180 to -120$)$ of the signals and also seismograms as white line overlays. a) Sequence of steps generated by a person walking towards and past the station along the summit. b) Signature of a small mass wasting event at the summit. c) Seismic signals during a rain event (note order of magnitude lower amplitudes). d) Seismic signature of a stress release event as described in Fig. 5. 

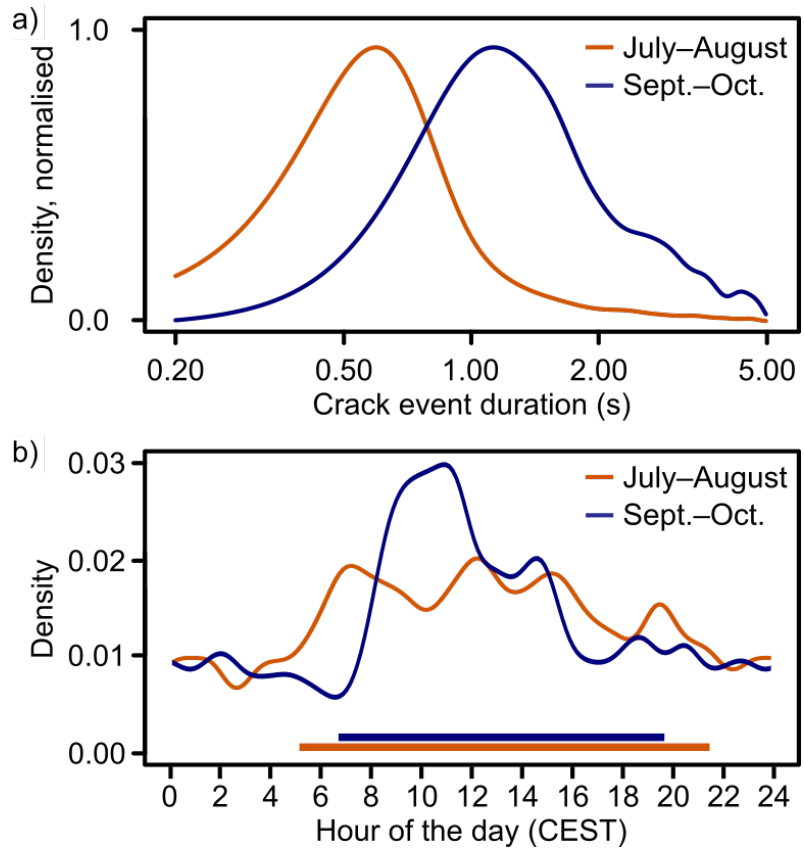

Figure 5. Properties of discrete stress release signals on the Hochvogel summit. a) Duration of signals. The kernel density estimate (0.1 s kernel bandwidth) depicts the log-normal distribution of signal duration, peaking at $0.58 \mathrm{~s}$ during July-August and $1.57 \mathrm{~s}$ during SeptemberOctober. b) Time of occurrence at the diurnal scale. Kernel density estimate ( $1 \mathrm{~h}$ kernel bandwidth) shows temporal clustering of events at different times during the two survey periods. Horizontal bars depict topography corrected sun rise and sunset times.

12 October, the average crack rate was lower, 18 per day. Episodes with enhanced crack activity occurred also during this period (e.g., 18, 20, 24-28, 03-07 October), but significantly less pronounced compared to the earlier interval. We note that the episodes of enhanced activity did not systematically coincide with precipitation events or weekend days when mountaineering traffic was likely more frequent. Individual events had an average duration of $0.58_{-0.02}^{+0.44} \mathrm{~s}$ (median and quartile range) during the first and $1.57_{-0.48}^{+0.95}$ $\mathrm{s}$ during the second period, both following a log-normal distribution (Fig. 5 a). The signals were clustered at the diurnal scale, occurring preferentially at day time (Fig. 5 b). That trend is even more pronounced during the second period.

Among the cases rejected because of their duration were events as shown in Fig. 4. These signals exhibited short, regularly spaced pulses (about 1.3 pulses per second) of systematically increasing and and decreasing amplitude (Fig. 4 a), or signals without distinct pulses but rather a spindle shaped energy envelope, increasing in amplitude for 4 $\mathrm{s}$ and decreasing for 7 seconds (Fig. 4 b). Likewise, during times of precipitation (Fig. 4 c), the sensors recorded up to $0.2 \mathrm{~s}$ long single pulses with mainly $60-80 \mathrm{~Hz}$ frequency content and decreasing recurrence intervals but higher amplitudes as the rain intensity increased (not shown).

\section{Discussion}

\subsection{Individual signals of summit activity}

According to our seismic data, cyclic activity in the Hochvogel summit occurs on diurnal and multi-day scales (Fig. 2). The diurnal cyclicity is expressed in systematic 
1-2 Hz changes of the vertical and horizontal component's fundamental frequency, in the HVSR bimodal frequency distribution, and in $d v / v$ fluctuations of about $0.2 \%$. These patterns are clearest in the more intact, northwest facing rock mass, and less so in the heavily fragmented rock mass facing towards the southeast. Multi-day cyclicity was prominent during the first survey period (10 July-01 August), expressed in several seismic observables. The vertical component fundamental frequency increased gradually over four to six day periods, alternating with two days of decreasing trends. Similarly, a pattern of 4-6 days stability with 2 day long interruptions of the bimodal frequency distribution pattern was found in the HVSR data. During these interruptions, $d v / v$ dropped by about $0.2 \%$, and the rate of short duration seismic events in the summit area increased by a factor of 0.5 to 7 . The significance of these coincidence is hard to estimate. However, tentatively we infer that these temporally connected signals are being driven by the same underlying mechanisms. To probe the nature of these drivers, we consider the individual seismic proxies (Fig. 2) in more detail.

\subsubsection{Fundamental frequency}

The fundamental frequency with which an object vibrates is at first order defined by its geometry and material properties. While the geometry of the Hochvogel summit can be considered relatively constant, at least during the time period covered in this study, the material properties are subject to changes. These can include thermal changes or variations in water content due to the local weather, and also internal mechanical changes due to rock mass fracturing, or the failure of rock bridges (Lévy et al., 2010; Moore et al., 2010). Similar to the range of values found in the Hochvogel summit, Lévy et al. (2010) reported a resonance frequency drop of almost $1 \mathrm{~Hz}$, paired with an increased rate of discrete seismic emissions in a limestone cliff in the Western Alps, just prior to a $21,000 \mathrm{~m}^{3}$ large failure event. Bottelin et al. (2013) measured and modelled the resonance frequency of a $1,000 \mathrm{~m}^{3}$ limestone slab in the Western Alps, finding systematic, thermally driven changes in the fundamental frequency. At the diurnal scale, increasing temperatures can cause an increasing fundamental frequency, with a time lag of a few hours due to heat dissipation into the rock. Bottelin et al. (2013) attribute this to stiffening of the interface between the column and the rock mass due to thermal expansion, likely involving temporary closure of rock fractures. In contrast, at the annual scale, rising temperatures result in a lower fundamental frequency (with a time lag of three months) due to a decreasing Young's modulus. Following this explanation of empirical and numerical modelling results, we interpret the diurnal cyclicity of our fundamental frequency data as representing the daily opening and closing of fractures in the rock mass, resulting in increased stiffness during warming and decreased stiffness during cooling.

In contrast, we did not observe a direct or lagged relation between fundamental frequency and air temperature on the multi-day scale. This may be due, in part, to the fact that the long-term temperature range is smaller than the diurnal range. Note also that our periods of observation were significantly shorter than the time lag of three months reported by Bottelin et al. (2013). Lévy et al. (2010) interpreted fundamental frequency drops as a global parameter characterizing the mass and its coupling to the stable rock mass. In the absence of any other likely cause we propose that slow increases in frequency were caused by cumulative increases of stress within the rock mass, which were then released episodically during a few days when frequency drops back to the values before the phase of stress increase. Similar drops of the fundamental frequency have also been reported to correlate with increased rock mass mobility values (e.g. Burjánek et al., 2018) and changes in the elastic moduli have been reported under stress in laboratory experiments (Barton, 2007; Draebing \& Krautblatter, 2012).

The different fundamental frequency windows of the vertical component $(24-28 \mathrm{~Hz}$, Fig. $2 \mathrm{a})$ and the horizontal component ( $8-10 \mathrm{~Hz}$, Fig. 2 b) may represent different modes of movement, possibly stamping in the vertical direction and either bending or rotating 
in the horizontal component. These mode dependent frequency differences were also described and modelled by Bottelin et al. (2013). In view of the complex structural situation and under-constrained geometric boundary conditions, numerical modelling of the rock mass properties appears not meaningful in the Hochvogel case and we desist from deduction of more detailed insights about the quantitative physical meaning of the fundamental frequency values.

\subsubsection{Horizontal-to-vertical spectral ratio}

HVSR data are thought to represent site resonance, solicited predominantly by Swaves and to a lesser degree by Rayleigh waves (Del Gaudio et al., 2014). Peaks in the ratio reflect the frequency at which the power of the horizontal component of a seismic signal significantly exceeds that of the vertical component, thus indicating a site specific resonance frequency. The method has been used in steep rock slope landscapes to monitor changes in system and material states, signaled by changes in the resonance frequency (e.g. Burjánek et al., 2012; Weber, Fäh, et al., 2018). These studies predominantly focused on seasonal to multi-year time spans to explore reversible and irreversible effects contributing to failure preparation. Like Weber, Fäh, et al. (2018) we have found multiple discrete fundamental frequency bands in the HVSR data (see SI). Here, we focus on the lowermost one, around 8-10 Hz (Fig. $2 \mathrm{c}$ ), which was also flagged in the fundamental frequency analysis (Fig. 2 b), indicating the spectral amplification effect due to the contribution of the horizontal component.

Our measurement intervals are not long enough to compare our data against reported findings on multi-seasonal time scales. However, we can explore the diurnal and the multi-day cyclicity patterns in the data. Our end-member modelling analysis has helped to identify and quantify the shape of the underlying frequency distributions and their contributions to the resulting normalised HVSR time series (Fig. 3). We interpret $\mathrm{EM}_{1}$, which predominantly contributes to the data during the night time (see downwards pointing arrows in Fig. 3 b) as indicative of a system with a lower resonance. This is supported by the evolution of the fundamental frequency of the horizontal component (Fig. 2 b) but at a higher temporal and spectral resolution. The lower resonance frequency may be caused, as described above, by thermal shrinkage which results in opening of small cracks and an overall decrease in the stiffness of the summit rocks. Vice versa, $\mathrm{EM}_{3}$ is the high resonance mode of the system, predominantly active during day time (green line and upwards pointing arrows in Fig. 3 b). $\mathrm{EM}_{2}$ can be regarded as the intermediate state between $\mathrm{EM}_{1}$ and $\mathrm{EM}_{3}$. We interpret $\mathrm{EM}_{4}$ as noise or residual end-member, accounting for the variability within the data set that is not covered by the three other end-members (for details see E. Dietze \& Dietze, 2019). During the second survey period, later in the year, $\mathrm{EM}_{4}$ had a different frequency range, around $2-5 \mathrm{~Hz}$, also visible in the raw HVSR data (Fig. $2 \mathrm{c}$ ). This frequency band had no special weight during the first survey period. Overall, the model quality $\left(R^{2}=0.89\right.$ for the first and $R^{2}=0.79$ for the second survey period) is comparable with results from other studies (cf. E. Dietze \& Dietze, 2019), implying that $89 \%$ and $79 \%$ of the system's variance can be explained by just four end-members.

Between the two monitoring intervals, end-members $\mathrm{EM}_{1}$ to $\mathrm{EM}_{3}$ moved to higher frequencies. This is likely due to the seasonally increasing temperature effect: overall higher temperatures within the rock result in thermal expansion and a stiffening of the rock mass. Likewise, the night time $\mathrm{EM}_{1}$ contributed systematically less to the data set in the second survey period (decrease from $42 \%$ to $19 \%$, see Fig. 3 d), while the day time $\mathrm{EM}_{3}$ gained importance (from $19 \%$ to $27 \%$ ). We attribute this to the decreasing time for the system to swing and remain in the low frequency mode during night time later in the year, due to the overall thermal input and heat legacy, and despite the gradually shorter day lengths. In the first survey period $\mathrm{EM}_{4}$ contributions were slightly stronger during the episodes of signal disturbance (yellow bars in Fig. 2). However, since we clipped the 
HVSR data at $15 \mathrm{~Hz}$ to isolate the part of the frequency spectrum that is dominated by daily variations, interpretation of this trend may be not meaningful. During the second monitoring interval, this effect was not found.

In summary, we consider the HVSR data (Fig. 2 c) and the estimated end-member loadings (Fig. $3 \mathrm{~d}$ ) and scores (Fig. $3 \mathrm{~b}$ ) to be a high resolution proxy for reversible material stiffness, as constrained by thermodynamics, predominantly at the diurnal scale, but also with an underlying seasonal trend.

\subsubsection{Seismic wave velocity evolution}

Relative changes of the seismic wave velocity are the summed effect of many contributing factors, and as for the fundamental frequency, these can be exogenic or endogenic in nature. Changes in seismic wave velocity can derive from variations of water saturation or freezing in pore space and fractures, ambient stress, for example exerted by gravity-driven deformation or ice pressure, and reflect changes in fracture extension and density (Barton, 2007; Draebing \& Krautblatter, 2012; Krautblatter \& Draebing, 2013). Temperature-driven changes are evident at the diurnal scale, with relatively low $d v / v$ values at the start and end of the day and relative maxima in the middle of the day (Fig. $2 \mathrm{~d}$ ). In contrast, the longer-term trends in temperature are not reflected in the $d v / v$ data set. Transitions from positive to negative temperatures, which would cause freezing of water and thus a drastic increase of the seismic wave velocity (James et al., 2019), did not affect the $d v / v$ time series. Elsewhere, the effect of rainwater infiltration is a lowering of the relative seismic wave velocity, both for deep groundwater systems (Clements \& Denolle, 2018) and shallow soil water content in the vadose zone (M. Dietze et al., submitted). However, rain (Fig. 2 e) had no easily discernable effects on the $d v / v$ data from the Hochvogel summit network. We remind that we have no direct rain measurements from the Hochvogel summit but used the rain gauge data from a station $12 \mathrm{~km}$ to the west. Under the rapidly changing and filigree weather conditions in the Alps, the representativeness of this rain data set may be limited. However, in the $d v / v$ data we see very few erratic changes that could be attributed to unrecorded rain events.

More importantly, we found cyclic patterns of slowly rising and suddenly dropping $d v / v$ values, with an amplitude of about $0.2 \%$ (Fig. $2 \mathrm{~d}$, bold black line), coincident with the periods of disturbance of the other proxy data. In the absence of meteorological forcing, we attribute these cycles to reversible, rock-internal material state changes. Increased stress has been reported to yield higher $d v / v$ values (Sens-Schönfelder \& Larose, 2010), and significant reductions in $d v / v$ values have been recorded immediately prior to the initiation of mass wasting processes (Mainsant et al., 2012). Following these findings, we interpret meteorologically unrelated and reversible $d v / v$ cycles as proxy for stress accumulation and dissipation within the rock mass.

\subsubsection{Emission of discrete seismic signals}

The different types of short seismic signal pulses recorded by the Hochvogel summit network (Fig. 4) have distinct properties, which make them straightforward to attribute to likely sources. Repeated, regularly spaced pulses with gradually increasing and decreasing amplitude (Fig. 4 a) are typical for people approaching and passing a seismic station (e.g., Vouillamoz et al., 2018). Several such sequences were recorded during installation and maintenance visits of the stations, and others registered only during day time when hikers frequent the summit. Spindle shaped continuous signals with rapidly increasing and less rapidly decreasing amplitudes lasting several seconds (Fig. 4 b) are indicative of small mass wasting events down the summit flanks. Similar signals have been described in detail by numerous other studies (e.g. Helmstetter \& Garambois, 2010; Hibert et al., 2011; Lacroix \& Helmstetter, 2011; Burtin et al., 2016) and their frequency spectrum is similar to artificial rock drop experiments (Weber, Fäh, et al., 2018). High- 
frequency signals unique to independently registered rain events (Fig. 4 c) are evident at all sensors but with random, incoherent drop impact signal timings at stations of the network. The pauses between the 0.05-0.2 s long pulses decrease after the onset of a rain event and become less evenly spaced. The frequency content of the signals is also higher $(60-80 \mathrm{~Hz})$ than for other recorded signals. We interpret such low amplitude signals as rain drop impacts at or very close to the seismic sensors. Finally, sudden pulses of 30$80 \mathrm{~Hz}$ signals without preceding or subsequent activity (Fig. 4 d) are most likely the result of sudden releases of accumulated stress by failing rock bridges or extension of cracks in the rock mass. Such signals have been reported under natural (Weber, Faillettaz, et al., 2018; Vouillamoz et al., 2018) and laboratory (Murton et al., 2016) conditions. We use this type of seismic signal as proxy for stress release, e.g. due to rock cracking.

Stress release signals had durations of $0.58_{-0.02}^{+0.44} \mathrm{~s}$ (median and quartile range) during the first, and $1.57_{-0.48}^{+0.95} \mathrm{~s}$ during the second period (Fig. $5 \mathrm{a}$ ). This increased duration of pulses may be due to the greater average travel distance of a signal to a sensor: only 2 stations instead of up to six during the first period, which results in extension due to scattering as waves travel through the rock medium, especially given that during the second period the two stations were separated by the main crack through the summit. More interestingly, stress release events appear to be linked to daylight conditions or, more specifically, potential insolation duration. During July-August, topography corrected sunrise was between 05:30 and 05:45 local time and sunset between 21:05 and 21:20, yielding a duration of potential insolation of between 15:20 and 15:45 hours. In contrast, during September-October sunrise was between 06:45 and 07:30 and sunset between 18:45 and 19:45, separated by 11:15 to 13:00 hours of potential sunlight (see horizontal bars in Fig. 5 b). Reflecting these insolation times, stress release events occurred preferentially between 05:00 and 22:00 local time during the first recording period, with a multimodal activity distribution. During the second survey period such events clustered between 7:00 and 21:00, with a pronounced maximum between 09:00 and 12:00.

At the multi-day scale, stress release events were not randomly distributed. Instead, we observed discrete bursts of a 150-600 \% activity increase above a relatively stable base line of 100 cracks per day (median) for the first recording period, and 18 cracks per day during the second period. These clusters coincided with the episodes of disturbance in the continuous proxy records (Fig. 2). During these episodes, the fundamental frequency of stations dropped, the bimodal frequency pattern of HVSR data was interrupted, and the local seismic velocity decreased.

An exception to the collocation of continuous seismic proxy adjustment and bursts of cracking is the prominent spike in stress release activity on 25 July. This could signal that there is a hierarchy of stress build up and release cycles within the Hochvogel summit, which has not been covered in its entirety by our short surveys. Alternatively, stress release in the summit is a process with cyclic and stochastic elements.

During the first survey period there were up to seven sensors in operation, with some brief, incidental intermissions of data transmission. In contrast, during the second survey period only two stations were operating, continuously and without any data gap. The average number of stations that detected the same seismic event was 3.5 during the first and 2 during the second survey period. Hence, there may be a network bias inherent to the time series. However, even if the number of true events were underestimated during the second period, it is unlikely that the general pattern of a significantly reduced event rate and overall number during that period is an artifact. Therefore, we conclude that there was a stark contrast in stress release activity between the first and the second survey period. A robust interpretation of this difference would only be possible in the context of a more extensive data set. 


\subsection{Synthesis}

With the interpretation of individual proxy data in hand, we can now investigate underlying system-wide dynamics. On the diurnal time scale, most likely due to thermal forcing, the Hochvogel summit experiences a cyclic increase and decrease of stress, but also strengthening and weakening of the coupling between the strongly fragmented southeastern and the less severely fragmented northwestern parts. Stress evolution is reflected throughout both survey periods and by multiple proxy data: i) the $d v / v$ data, which records the effects of increased stress as higher $d v / v$ values, and ii) discrete stress release signals predominantly during daylight conditions. The coupling evolution is evidenced by i) the vertical fundamental frequency of the northwestern summit part, ii) the horizontal fundamental frequency of the southeastern instable summit part, and iii) the HVSR end-member time series. The predominant effect of thermal forcing may be interpreted based on i) the clear diurnal air temperature signal in line with the patterns of all seismic proxy data, ii) the agreement of day lengths and stress release signals at the seasonal scale, and finally iii) the absence of evidence for any other plausible forcing mechanism.

The short sub-diurnal reaction time of the system implies that both stress release and coupling adjustment must be implemented at or very close to the surface, and are thus unlikely to have a significant effect on the wholesale slope instability, especially at many metres depth. Heat as driver for this system is in agreement with the effects that we have measured seismically. That heat can be provided either by direct insolation or as sensible heat of the air circulating around the summit and into the cracks. It would be dissipated by conduction, either directly within the rock or through percolating water, which is able communicate thermal effects deeper into the rock, and thereby attenuate the expressions of heat input close to the surface. Regardless of the mechanism, heat diffusion into the rock would result in time lags of several hours (e.g., $37 \mathrm{~h}$ for $50 \mathrm{~cm}$ and $60 \mathrm{~h}$ for $1 \mathrm{~m}$, Mulas et al., 2020) and rapid dampening (e.g., Collins et al., 2018) of the thermal input signal. Indeed, the end-member evolution with day time (especially for $\mathrm{EM}_{1}$ and $\mathrm{EM}_{3}$, Fig. 3 b) shows that the low frequency $\mathrm{EM}_{1}$ usually decreases gradually with the course of the day, whereas the high frequency $\mathrm{EM}_{3}$ correspondingly increases throughout day time.

The coupling adjustment shows no signs of progressive evolution. Continuously less cracks capable of closing during day time and thus a systematic decrease in the fundamental frequency is not evident from our data during the study interval. We rather see the opposite effect: a systematically rising frequency of the end-member's modal frequencies. However, at least one full year of monitoring would be required to investigate whether the fundamental frequency returns to the values after one annual cycle through all seasons, or whether there is an offset indicative of progressive weakening (cf. Weber, Fäh, et al., 2018).

Stress release signals in the form of short seismic pulses do also argue for an irreversible component in the consequences of the diurnal forcing regime. The thermally driven physical weathering very close to the surface contributes to flaking (Collins et al., 2018) and leads to extended water pathways, which in turn increases infiltration capacity and circulation dynamics, basic foundations for subsequent weathering processes. On top of diurnal cycles, the trends of $d v / v$ values continuously increasing for four to seven days before dropping for a few days, imply a systematic conditioning of the Hochvogel summit that results in increased accumulated stress that is episodically released and thereby emits an increased amount of short seismic pulses beyond the typical daily rate. The $d v / v$ proxy, especially as it is based on the $4-16 \mathrm{~Hz}$ frequency window, representing wave lengths of tens of metres, integrates mechanical effects significantly beyond just the top few millimetres of the rock mass (Snieder, 2004; Larose et al., 2015). Thus, together with the non-diurnal cyclicity pattern, we see evidence for a process that is disconnected from the 
set of meteorological drivers and rather points at a mechanism that is active inside and driven by endogenic dynamics of the instable rock mass.

Stick-slip behaviour has been found in several large mass wasting events prior to catastrophic failure (e.g., Yamada et al., 2016; Poli, 2017; Schöpa et al., 2018). Whereas this precursor signal appears to bear an exploitable potential for hazard early warning strategies during the final part of the preparation stage of an event, little is known about the earlier stages of preparation. This is because stick slip motion is overall hard to detect when the intervals between slip events are long in relation to the monitoring period. Seismically, slip events manifest as periods of increased seismic activity, predominantly through the emission of short pulses $(<2 \mathrm{~s}$ ) of $30-80 \mathrm{~Hz}$ signals (Poli, 2017; Vouillamoz et al., 2018; Weber, Faillettaz, et al., 2018). In the Hochvogel summit, we also evidence 1-2 day long periods of increased seismic activity exhibiting these pulse-like properties, that result in a drop of the $d v / v$ stress proxy, separated by several days of just background activity during which we see the buildup of stress. We interpret this multi-day cyclic pattern as an early stage of stick-slip evolution of the instable rock mass at the summit. We propose that during the stick phase gravity pulls the rock mass down slope, causing elastic deformation (background seismic pulse emissions), which causes buildup of stress (increase of $d v / v$ ) until eventually the rock mass slips and thereby emits more seismic signals and the stress within the rock mass is reduced. We anticipate that as failure preparation of the Hochvogel rock mass progresses, this frequency of slip events increases, and immediately prior to failure, these patterns can turn into a continuous tremor-like signal with a frequency of several per second (Schöpa et al., 2018).

Throughout the analysed proxy data we identified superimposed cycles of mechanisms that drive the evolution of the slope instability. In addition, the period of increased stress release pulses on 25-26 August (Fig. $2 \mathrm{f}$ ) points at a further mechanism, which may be of stochastic or higher hierarchy nature. The differences in all proxy time series between the first and second survey period may suggest also a seasonal component contributing to the preparation phase of the failure. However, in order to reveal these potentially additional components, and to fully constrain the progressive evolution towards the final stage of the mass movement, we would need a longer, complete data set from a constant and sufficiently dense seismic network on the summit - obviously a task of future research at this site.

We have presented a multi proxy based anatomy of a major future slope failure during a key stage of its preparation phase, which is inherently difficult to survey. We propose that it is possible to generalise the Hochvogel observations to also describe the fate of other high mountain peaks prone to failure. Most seismic proxies can be measured and interpreted in a similar way as for the case presented here. However, the outcomes of this study have also shown that it will be key to design a system that is reliable and capable of operating under the hostile environmental conditions encountered at this solitary peak. Such a system should ideally also probe the surface expressions of the evolution the rock mass undergoes, for example by dedicated direct measurements of crack opening, reference point position tracking and surface as well as below-surface temperature and moisture logs. That way, the seismically sensed effects can be linked more directly to other first order physical quantities and thus allow for a distributed, continuous and effective survey of a hitherto enigmatic yet essential phase in the evolution of landscapes dominated by steep slopes.

\section{Acknowledgments}

The AlpSense team is thanked for logistic support, data provision and discussion. Udo is thanked for safe and amazing transits. We explicitly thank Torsten Queißer for continuous efforts on station construction and maintenance. We thank Ben Huxol, Nora Krebs, Gunnar Pruß and Anne Voigtländer for maintenance efforts. 


\section{References}

Allen, R. (1982). Automatic phase pickers: Their present use and future prospects. Bulletin of the Seismological Society of America, 72, S225-S242.

Allstadt, K. (2013). Extracting source characteristics and dynamics of the august 2010 mount meager landslide from broadband seismograms. Journal of Geophysical Research: Earth Surface, 118(3), 1472-1490. doi: 10.1002/jgrf.20110

Assefa, S., McCann, C., \& Sothcott, J. (2003). Velocities of compressional and shear waves in limestones. Geophysical Prospecting, 51(1), 1-13. doi: 10.1046/j.1365 $-2478.2003 .00349 . x$

Barton, N. (2007). Rock quality, seismic velocity, attenuation and anisotropy. Taylor and Francis.

Borri-Brunetto, M., Carpinteri, A., \& Chiaia, B. (2003). The effect of scale and criticality in rock slope stability. Rock Mechanics and Rock Engineering, 37, 117126. doi: 10.1007/s00603-003-0004-1

Bottelin, P., Lévy, C., Baillet, L., Jongmans, D., \& Guéguen, P. (2013). Modal and thermal analysis of les arches unstable rock column (vercors massif, french alps). Geophysical Journal International, 194, 849-858. doi: $10.1093 /$ gji/ggt046

Burjánek, J., Gischig, V., Moore, J., \& Fäh, D. (2018). Ambient vibration characterization and monitoring of a rock slope close to collapse. Geophysical Journal International, 212, 297-310. doi: 10.1093/gji/ggx424

Burjánek, J., Moore, J., Yugsi Molina, F., \& Fäh, D. (2012). Instrumental evidence of normal mode rock slope vibration. Geophysical Journal International, 188, $559-569$.

Burtin, A., Hovius, N., McArdell, B. W., Turowski, J. M., \& Vergne, J. (2014). Seismic constraints on dynamic links between geomorphic processes and routing of sediment in a steep mountain catchment. Earth Surface Dynamics, 2, 21-33. doi: 10.5194/esurf-2-21-2014

Burtin, A., Hovius, N., Milodowski, D. T., Chen, Y.-G., Wu, Y.-M., Lin, C.-W., ... Leu, P.-L. (2013). Continuous catchment-scale monitoring of geomorphic processes with a 2-d seismological array. Journal of Geophysical Research Earth Surface, 118, 19561974. doi: 10.1002/jgrf.20137

Burtin, A., Hovius, N., \& Turowski, J. M. (2016). Seismic monitoring of torrential and fluvial processes. Earth Surface Dynamics, 4, 285-307. doi: 10.5194/esurf $-4-285-2016$

Clements, T., \& Denolle, M. A. (2018). Tracking groundwater levels using the ambient seismic field. Geophysical Research Letters, 45(13), 6459-6465. doi: 10 .1029/2018GL077706

Collins, B., Stock, G., Eppes, M.-C., Lewis, S., Corbett, S., \& Smit, J. (2018). Thermal influences on spontaneous rock dome exfoliation. Nature Communications, 9:762, 1-12. doi: 10.1038/s41467-017-02728-1

Cook, K. L., Andermann, C., Gimbert, F., Adhikari, B. R., \& Hovius, N. (2018). Glacial lake outburst floods as drivers of fluvial erosion in the himalaya. Science, 362 (6410), 53-57. doi: 10.1126/science.aat4981

D'Amato, J., Hantz, D., Guerin, A., Jaboyedoff, M., Baillet, L., \& Mariscal, A. (2016). Influence of meteorological factors on rockfall occurrence in a middle mountain limestone cliff. Natural Hazards and Earth System Sciences, 16(3), 719-735. doi: 10.5194/nhess-16-719-2016

Dammeier, F., Moore, J. R., Haslinger, F., \& Loew, S. (2011). Characterization of alpine rockslides using statistical analysis of seismic signals. Journal of Geophysical Research, 116, F04024. doi: 10.1029/2011JF002037

Del Gaudio, V., Muscillo, S., \& Wasowski, J. (2014). What we can learn about slope response to earthquakes from ambient noise analysis: an overview. Engineering Geology, 182, 182-200. 
Dietze, E., \& Dietze, M. (2019). Grain-size distribution unmixing using the r package emmageo. Quaternary Science Journal, 68(1), 29-46. doi: 10.5194/egqsj $-68-29-2019$

Dietze, M. (2018a). 'eseis' - an $r$ software toolbox for environmental seismology. $v$. 0.4.0. GFZ Data services. doi: 10.5880/GFZ.5.1.2018.001

Dietze, M. (2018b). The r package "eseis" - a software toolbox for environmental seismology. Earth Surface Dynamics, 6, 669-686. doi: 10.5194/esurf-6-669 $-2018$

Dietze, M., Cook, K., Illien, L., Rach, O., Puffpaff, S., Stodian, I., \& Hovius, N. (submitted). Impact of nested moisture cycles on cliff coast failure revealed by multi-seasonal seismic and topographic surveys. Journal of Geophysical Research: Earth Surface. doi: https://eartharxiv.org/wuvdr/

Dietze, M., \& Krautblatter, M. (2020). Seismic data from the hochvogel summit array. v. 0.1.0. GFZ Data services. doi: 10.5880/GFZ.4.6.2020.005

Dietze, M., Mohadjer, S., Turowski, J., Ehlers, T., \& Hovius, N. (2017). Validity, precision and limitations of seismic rockfall monitoring. Earth Surface Dynamics, 2017, 1-23. doi: 10.5194/esurf-2017-12

Dietze, M., Turowski, J. M., Cook, K. L., \& Hovius, N. (2017). Spatiotemporal patterns, triggers and anatomies of seismically detected rockfalls. Earth Surface Dynamics, 5(4), 757-779. doi: 10.5194/esurf-5-757-2017

Di Maio, C., Vassallo, R., Vallario, M., Pascale, S., \& Sdao, F. ～(2010). Structure and kinematics of a landslide in a complex clayey formation of the italian southern apennines. Engineering Geology, 116(3), 311 - 322. doi: https://doi.org/10.1016/j.enggeo.2010.09.012

Dixon, N., Smith, A., Flint, J. A., Khanna, R., Clark, B., \& Andjelkovich, M. (2018). An acoustic emission landslide early warning system for communities in low-income and middle-income countries. Lanslides, 15, 1631-1644. doi: 10.1007/s10346-018-0977-1

Draebing, D., \& Krautblatter, M. (2012). P-wave velocity changes in freezing hard low-porosity rocks: a laboratory-based time-average model. The Cryosphere, 6 , $1163-1174$.

DWD. (2019). Climate data centre. Retrieved from https://www.dwd.de/EN/ climate_environment/cdc/cdc_node.html

Einstein, H., Veneziano, D., Baecher, G., \& O'Reilly, K. (1983). The effect of discontinuity persistence an rock slope stability. International Journal of Rock Mechanics, Mineral Science and Geomechanics Abstracts, 20, 227-236.

Ekström, G., \& Stark, C. P. (2013). Simple Scaling of Catastrophic Landslide Dynamics. Science, 339, 1416-1419. doi: 10.1126/science.1232887

Frayssines, M., \& Hantz, D. (2006). Failure mechanisms and triggering in calcareous cliffs of the subalpine ranges (french alps). Engineering Geology, 86, 256-270. doi: 10.1016/j.enggeo.2006.05.009

Fuchs, F., Lenhardt, W., Bokelmann, G., \& the AlpArray Working Group. (2018). Seismic detection of rockslides at regional scale: examples from the eastern alps and feasibility of kurtosis-based event location. Earth Surface Dynamics, 6(4), 955-970. doi: 10.5194/esurf-6-955-2018

Hammer, C., Ohrnberger, M., \& Schlindwein, V. (2015). Pattern of cryospheric seismic events observed at ekstrom ice shelf, antarctica. Geophysical Research Letters, 42, 3936-3943. doi: 10.1002/2015GL064029

Helmstetter, A., \& Garambois, S. (2010). Seismic monitoring of sechilienne rockslide (french alps): Analysis of seismic signals and their correlation with rainfalls. Journal of Geophysical Research, 115, F03016. doi: 10.1029/2009JF001532

Hibert, C., Mangeney, A., Grandjean, G., \& Shapiro, N. M. ～(2011). Slope instabilities in dolomieu crater, runion island: From seismic signals to rockfall characteristics. Journal of Geophysical Research, 116, F04032. doi: 10.1029/2011JF002038 
Hobiger, M., Wegler, U., Shiomi, K., \& Nakahara, H. (2014). Single-station crosscorrelation analysis of ambient seismic noise: application to stations in the surroundings of the 2008 iwate-miyagi nairiku earthquake. Geophysical Journal International, 198(1), 90-109.

James, S., Knox, H., Abbott, R., Panning, M., \& Screaton, E. (2019). Insights into permafrost and seasonal activelayer dynamics from ambient seismic noise monitoring. Journal of Geophysical Research: Earth Surface, 124. doi: 10.1029/2019JF005051

Kemeny, J. (2003). The time-dependent reduction of sliding cohesion due to rock bridges along discontinuities: A fracture mechanics approach. Rock mechanics and Rock Engineering, 36, 27-38. doi: 10.1007/s00603-002-0032-2

Krautblatter, M., \& Draebing, D. (2013). Pseudo 3d p wave refraction seismic monitoring of permafrost in steep unstable bedrock. Journal of Geophysical Research: Earth Surface, 119, 287-299. doi: 10.1002/2012JF002638

Krautblatter, M., Mayer, C., Münzer, U., Siegert, F., Stilla, U., Wunderlich, T., ... Plsken, R. (2019). The alpsense-project: Alpine remote sensing of climateinduced naturalhazards. Geophysical Research Abstracts, 21, 17541.

Lacroix, P., \& Helmstetter, A. (2011). Location of seismic signals associated with microearthquakes and rockfalls on the schilienne landslide, french

alps. Bulletin of the Seismological Society of America, 101, 341-353. doi: $10.1785 / 0120100110$

Larose, E., Carriere, S., Voisin, C., Bottelin, P., Baillet, L., Guéguen, P., ... Massey, C. (2015). Environmental seismology: What can we learn on earth surface processes with ambient noise? Journal of Applied Geophysics, 116, 62-74. doi: 10.1016/j.jappgeo.2015.02.001

Leith, K., Moore, J., Amann, F., \& Loew, S. ～(2014). In situ stress control on microcrack generation and macroscopic extensional fracture in exhuming bedrock. Journal of Geophysical Research: Solid Earth, 119(594-615). doi: 10.1002/2012JB009801

Lévy, C., Baillet, L., Jongmans, D., Mourot, P., \& Hantz, D. (2010). Dynamic response of the chamousset rock column (western alps, france). Journal of Geophysical Research: Earth Surface, 115(F4). doi: 10.1029/2009JF001606

Mainsant, G., Larose, E., Broennimann, C., Michoud, C., \& Jongmans, D. (2012). Abient seismic noise monitoring of a clay land-slide: toward failure prediction. Journal of Geophysical Research, 39(L19301). doi: 10.1029/2011JF002159

Moore, J., Gischig, V., Burjánek, J., Loew, S., \& Fäh, D. （2010). Site effects in unstable rock slopes: dynamic behavior of the randa instability (switzerland). Journal of Geophysical Research, 101, 3110-3116. doi: 10.1785/0120110127

Mulas, M., Marnas, M., Ciccarese, G., \& Corsini, A. (2020). Sinusoidal wave fit indexing of irreversible displacements for crackmeters monitoring of rockfall areas: test at pietra di bismantova (northern apennines, italy). Landslides, 17, 231-240. doi: 10.1007/s10346-019-01281-w

Murton, J., Kuras, O., Krautblatter, M., Cane, T., Tschofen, D., Uhlemann, S., ... Watson, P. (2016). Site effects in unstable rock slopes: dynamic behavior of the randa instability (switzerland). Journal of Geophysical Research: Earth Surface, 121, 2309-2332. doi: 10.1002/2016JF003948

Nakamura, Y. (1989). A method for dynamic characteristics estimations of subsurface using microtremors on the ground surface. Railw. Tech. Res. Inst. Quart. Rep., 30, 25-33.

Nogoshi, M., \& Igarashi, T. (1971). On the amplitude characteristics of microtremor -part 2 (in japanese with english abstract). Journal of the Seismological Society of Japan, 24, 26-40.

Overduin, P. P., Haberland, C., Ryberg, T., Kneier, F., Jacobi, T., Grigoriev, M. N., \& Ohrnberger, M. (2015). Submarine permafrost depth from ambient seismic noise. Geophysical Research Letters, 42(18), 7581-7588. doi: 
10.1002/2015GL065409

Pérez-Guillén, C., Tsunematsu, K., Nishimura, K., \& Issler, D. (2019). Seismic location and tracking of snow avalanches and slush flows on mt. fuji, japan. Earth Surface Dynamics, 7(4), 989-1007. doi: 10.5194/esurf-7-989-2019

Poli, P. (2017). Creep and slip: Seismic precursors to the nuugaatsiaq landslide (greenland). Geophysical Research Letters, 44, 8832-8836. doi: 10.1002/2017GL075039

R Development Core Team. (2020). R: A Language and Environment for Statistical Computing [Computer software manual]. Vienna, Austria. Retrieved from http://CRAN.R-project.org

Saettele, M., Krautblatter, M., Brndl, M., \& Straub, D. (2015). Forecasting rock slope failure: how reliable and effective are warning systems? Landslides(13), 737-715. doi: 10.1007/s10346-015-0605-2

Schöpa, A., Chao, W.-A., Lipovsky, B. P., Hovius, N., White, R. S., Green, R. G., \& Turowski, J. M. (2018). Dynamics of the askja caldera july 2014 landslide, iceland, from seismic signal analysis: precursor, motion and aftermath. Earth Surface Dynamics, 6(2), 467-485. doi: 10.5194/esurf-6-467-2018

Senfaute, G., Duperret, A., \& Lawrence, J. A. (2009). Micro-seismic precursory cracks prior to rock-fall on coastal chalk cliffs: a case study at mesnil-val, normandie, nw france. Natural Hazards and Earth System Sciences, 9(5), 1625-1641. doi: 10.5194/nhess-9-1625-2009

Sens-Schönfelder, C., \& Larose, E. (2010). Lunar noise correlation, imaging and monitoring. Earthquake Science, 23, 510-530.

Sens-Schönfelder, C., \& Wegler, U. (2006). Passive image interferometry and seasonal variations of seismic velocities at merapi volcano, indonesia. Geophysical Research Letters, 33(21).

Snieder, R. (2004). Extracting the green's function from the correlation of coda waves: A derivation based on stationary phase. Phys. Rev. E, 69, 046610. doi: 10.1103/PhysRevE.69.046610

Stock, G., Collins, B., Santaniello, D., Zimmer, V., Wieczorek, G., \& Snyder, J. (2013). Historical rock falls in yosemite national park. U.S. Geological Survey Data Series 746, 746, 17.

Voigtländer, A., Leith, K., \& Krautblatter, M. (2018). Subcritical crack growth and progressive failure in carrara marble under wet and dry conditions. Journal of Geophysical Research: Solid Earth, 123, 3780-3798. doi: 10.1029/2017JB014956

Vouillamoz, N., Rothmund, S., \& Joswig, M. (2018). Characterizing the complexity of microseismic signals at slow-moving clay-rich debris slides: the super-sauze (southeastern france) and pechgraben (upper austria) case studies. Earth Surface Dynamics, 6(2), 525-550. doi: 10.5194/esurf-6-525-2018

Walter, F., Amann, S., Kos, A., Kenner, R., Phillips, M., de Preux, A., ... Bonanomi, Y. (2020). Direct observations of a three million cubic meter rockslope collapse with almost immediate initiation of ensuing debris flows. Geomorphology, 351, 106933.

Weber, S., Fäh, D., Beutel, J., Faillettaz, J., Gruber, S., \& Vieli, A. (2018). Ambient seismic vibrations in steep bedrock permafrost used to infer variations of ice-fill in fractures. Earth and Planetary Science Letters, 501, 119-127.

Weber, S., Faillettaz, J., Meyer, M., Beutel, J., \& Vieli, A. (2018). Acoustic and microseismic characterization in steep bedrock permafrost on matterhorn (ch). Journal of Geophysical Research: Earth Surface, 123, 1363-1385.

Welch, I., \& McLamore, V. (1973). The ambient vibration survey. Proceedings of Fifth World Conference on Earthquake Engineering, Rome, 286-289.

Welch, P. (1967). The use of fast fourier transform for the estimation of power spectra: A method based on time averaging over short, modified periodograms. IEEE Transactions on Audio and Electroacoustics, 15, 70-73. 
Yamada, M., Mori, J., \& Matsushi, Y. (2016). Possible stick-slip behavior before the rausu landslide inferred from repeating seismic events. Geophysical Research Letters, 43(17), 9038-9044. doi: 10.1002/2016GL069288 